\section{Correspondence}

https://doi.org/10.11646/zootaxa.4985.4.13

http://zoobank.org/urn:lsid:zoobank.org:pub:B3FA62CC-63C2-4765-B329-059D913A1838

\title{
On the correct authorship, spelling, and type species of genus Dasongius (Pauropoda: Pauropodidae)
}

\author{
CARLOS A. MARTÍNEZ-MUÑOZ1 \& YUN BU ${ }^{2}$ \\ ${ }^{1}$ Zoological Museum, Biodiversity Unit. FIN-20014 University of Turku, Finland. \\ "=|archilegt@gmail.com; @i https://orcid.org/0000-0003-4345-120X \\ ${ }^{2}$ Natural History Research Center, Shanghai Natural History Museum, Shanghai Science \& Technology Museum, Shanghai 200041, \\ China. \\ ”- buy@sstm.org.cn; @ https://orcid.org/0000-0002-7177-9686
}

The genus Songius Sun \& Guo in Guo et al., 2010 (Pauropoda: Pauropodidae) was established for two new species from China: Songius rugosus Sun \& Guo in Guo et al., 2010 and Songius bicruris Guo \& Sun in Guo et al., 2010. The manuscript was received by the journal Zoological Science on $7^{\text {th }}$ April 2010 and the article is displayed on the BioOne platform with the publication date of $1^{\text {st }}$ November 2010. In the same year, Yin et al. (2010) established the genus Songius Yin \& Li in Yin et al., 2010 (Coleoptera: Staphylinidae: Pselaphinae).

According to Qian et al. (2015: 533) the publication date of the article by Yin et al. (2010) is June 2010. Therefore, Qian et al. (2015: 533) recognized the genus Songius Sun \& Guo in Guo et al., 2010 as a junior homonym of the genus Songius Yin \& Li in Yin et al., 2010, and proposed a new replacement name for the junior homonym.

Qian et al. (2015: 532) wrote "Dasonguis (Sun \& Guo, 2010) nom. nov.” and "Dasongius (Sun \& Guo, 2010) new name (= Songius Sun \& Guo, 2010)". In doing so, they made two mistakes:

(1) They proposed multiple original spellings (two) in the sense of article 19.3 of the Code (ICZN 1999). To the best of our knowledge, no author has yet acted as the First Reviser (articles 24.2.3 and 24.2.4) of the two original spellings involved. In citing both, we hereby fix Dasongius as the etymologically correct original spelling, and regard Dasonguis as an unavailable, incorrect original spelling.

(2) They incorrectly stated the authorship of their new replacement name. Bu (2021: 240), following Qian et al. (2015), also wrote “Genus Dasongius Sun \& Guo, 2010”. Qian et al. (2015) missed that the authorship of junior homonyms without synonyms is ruled by article 60.3 of the Code. A new substitute name bears its own author and date. The correct authorship of the replacement name Dasongius is thus Qian, Dong, Bernard \& Sun, 2015.

The type species of Dasongius was cited by Qian et al. (2015: 533) as "Type species: Dasongius rugosus (Sun \& Guo, 2010) new combination (= Songius rugosus Sun \& Guo, 2010)", and later by Bu (2021: 240) as "Type species. Dasongius rugosus (Sun \& Guo, 2010)". Such treatment is not erroneous, but we encourage subsequent authors to follow Recommendation 67B of the Code and to cite the type species of Dasongius by its original binomen, Songius rugosus Sun \& Guo in Guo et al., 2010. If desired, the valid name Dasongius rugosus (Sun \& Guo in Guo et al., 2010) may be cited in addition.

\section{Additional remarks:}

Remark 1: Guo et al. (2010: 896) attributed the authorship of the family Pauropodidae to "Lubbock, 1867", most likely following the classification by Scheller (2008: 3). The name had been published in the Transactions of the Linnean Society of London, volume 26, part 1, consisting of pp. 1-352 and plates 1-22. According to Raphael (1970: 71), there are two competing publication dates for volume 26, part 1: either $5^{\text {th }}$ March 1868 or $11^{\text {th }}$ April 1868. Here we adopt the earliest date for the purpose of recording in Myriapoda. Regardless of the chosen date, the authorship of the family Pauropodidae is "Lubbock, 1868", as long as it is linked to the Transactions, volume 26, part 1. A source of future confusion may be that Lubbock $(1867,1868)$ used the same article title, "On Pauropus, a new type of centipede", for two different publications, both mentioned in the reference list below. Only the latter contains the family name Pauropodidae.

Remark 2: Guo et al. (2010: 896) attributed the authorship of the subfamily Pauropodinae to "Verhoeff, 1934", most likely following Scheller (2008: 5). The correct authorship of the subfamily is ruled by the Principle of Coordination ap- 
plied to family-group names, article 36.1 of the Code. A name established for a taxon at any rank in the family group is deemed to have been simultaneously established for nominal taxa at all other ranks in the family group. The family-rank name Pauropodidae was first proposed by Lubbock (1868: 182). The correct authorship of the coordinated subfamily name Pauropodinae is thus "Lubbock, 1868".

Remark 3: Qian et al. (2015: 533) wrote "Other species: Dasongius bicrurus (Guo \& Sun, 2010) new combination (= Songius bicrurus Guo \& Sun, 2010)". Those names contain the specific epithet "bicrurus", different from the original epithet "bicruris". The two names do not represent a mandatory change or an emendation, as evidenced by the correct spelling Dasongius bicruris mentioned three times by Qian et al. $(2015: 522,533,536)$. The misspelled names are thus incorrect subsequent spellings in the sense of article 33.3 of the Code, and as such are unavailable. The misspelled epithet "bicrurus" was inadvertently repeated by Bu (2021: 244) once, along with four mentions of the correct original spelling "bicruris".

Remark 4: Guo \& Sun in Guo et al. (2010: 897) wrote about the etymology of Songius bicruris: "From the Latin $b i=$ two and cruris = branch (referring to the appendages of the anal plate)". The authors did not indicate whether they regarded "bicruris" as a noun or as an adjective. It is here regarded as a nominative singular, masculine, third declension adjective. The adjective is listed by Eckel (2011), as "bicruris,-e (adj.B): with two legs [i.e., segments or divisions]". The abbreviation "adj.B" was used by Eckel (2011) to indicate third declension adjectives. The expression "bicruris,-e" highlights that this third declension adjective is in the nominative singular, and that it belongs to one main form in which masculine and feminine are the same, and neuter is different. Therefore, "bicruris" satisfies article 11.9.1.1. of the Code, as an adjective in the nominative singular. According to article 31.2 of the Code, a species-group name which is a Latin adjective in the nominative singular, must agree in gender with the generic name with which it is at any time combined. The adjective "bicruris" agrees in gender with the masculine genus name Dasongius, and with any feminine generic name with which it may be combined in the future. If ever combined with a neuter genus name, "bicruris" must be declined to "bicrure".

\section{Biodiversity Informatics recording:}

1) Names: The following 16 taxonomic names are recorded in Myriatrix (The Fellegship of the Rings 2020 onwards), the virtual research environment for Myriapoda and Onychophora proposed by Martínez-Muñoz (2019). Recording is deemed complete for the genus Dasongius and its subordinated names.

1. Class Pauropoda Lubbock, 1868

2. Order Tetramerocerata Remy, 1950

3. Superfamily Pauropodidae Lubbock, 1868

4. Family Pauropodidae Lubbock, 1868

5. Subfamily Pauropodinae Lubbock, 1868

6. Genus Dasongius Qian, Dong, Bernard \& Sun, 2015; replacement name pro Songius Sun \& Guo in Guo et al., 2010, a junior homonym of Songius Yin \& Li in Yin et al., 2010 (Coleoptera: Staphylinidae: Pselaphinae)

7. Dasonguis Qian, Dong, Bernard \& Sun, 2015; unavailable, incorrect original spelling pro Dasongius Qian, Dong, Bernard \& Sun, 2015

8. Songius Sun \& Guo in Guo et al., 2010; invalid, junior homonym of Songius Yin \& Li in Yin et al., 2010 (Coleoptera: Staphylinidae: Pselaphinae)

9. Dasongius bicruris (Guo \& Sun in Guo et al., 2010)

10. Dasongius bicrurus (Guo \& Sun in Guo et al., 2010); unavailable, incorrect subsequent spelling

11. Songius bicruris Guo \& Sun in Guo et al., 2010

12. Songius bicrurus Guo \& Sun in Guo et al., 2010; unavailable, incorrect subsequent spelling

13. Dasongius rugosus (Sun \& Guo in Guo et al., 2010)

14. Songius rugosus Sun \& Guo in Guo et al., 2010

15. Dasongius liupanensis $\mathrm{Bu}, 2021$

16. Dasongius spatulatus $\mathrm{Bu}, 2021$

2) Diagnoses: We compiled ten relevant taxonomic diagnoses (see numbers in bold in the list above) and rewrote them when necessary. Taxon pages were created in Myriatrix and all diagnoses were recorded on the respective taxon page, section "Diagnostic description", and additionally in a supplementary file (https://doi.org/10.5281/zenodo.4682989). Diagnoses for taxa in the higher classification of Pauropoda (class to family-group) follow Scheller (2008; 2011), the diagnosis 
of Pauropoda being rewritten with increased consistency. Diagnosis of genus Dasongius follows Guo et al. (2010: 896) and $\mathrm{Bu}$ (2021: 240). Diagnoses of Dasongius species follow their original descriptions, with the necessary standardization and a few corrections made in this work. To the extent possible, the diagnoses follow a morphological progression from anterior to posterior and from dorsal to ventral. Diagnoses above the species level provide an anchoring element by referring to the parent taxon in the first sentence.

3) Publications: All taxonomic publications cited in the reference list at the end of this work, including the Coleoptera article by Yin et al. (2010) containing one senior homonym, are registered in the literature database of Myriatrix. Recording of publications included filling the "Date Published" field with the most accurate date available, in the format $\mathrm{DD} / \mathrm{MM} / \mathrm{YYYY}$.

\section{Acknowledgements:}

The Natural History Museum, London continuously supports maintenance of Myriatrix. Dr. Daniel Whitmore (Staatliches Museum für Naturkunde Stuttgart, Germany), the Turku University Library (Finland), and the Biodiversity Heritage Library provided access to literature. Dr. Alessandro Minelli (University of Padova, Italy) kindly checked the first version of this draft and his advice led to rewriting Remark 4. Zootaxa editor Dr. Thomas Wesener provided useful guidance and Dr. Ivan Tuf conducted the review process. Reviews by Dr. Sergei Golovatch (Russian Academy of Sciences, Moscow, Russia) and Dr. Alessandro Minelli improved the quality of the manuscript.

\section{References:}

Bu, Y. (2021) Two new species of the genus Dasongius (Myriapoda, Pauropoda, Pauropodidae) from China. Zootaxa, 4908 (2), 239-250. https://doi.org/10.11646/zootaxa.4908.2.5

Eckel, P.M. (2011) A Grammatical Dictionary of Botanical Latin. Missouri Botanical Garden. Available from: http://www. mobot.org/mobot/LatinDict/search.aspx (accessed 1 March 2021)

Guo, H., Sun, H.-Y., Qian, C.-Y., Shen, H. \& Zhou, K.-Y. (2010) A new genus and two new species of the subfamily Pauropodinae (Myriapoda: Pauropoda: Pauropodidae) from China. Zoological Science, 27 (11), 895-899. https://doi.org/10.2108/zsj.27.895

ICZN (1999) International Code of Zoological Nomenclature. $4^{\text {th }}$ Edition. The International Trust for Zoological Nomenclature, London, $306 \mathrm{pp}$.

Lubbock, J. (1867) On Pauropus, a new type of centipede. Journal of the Linnean Society of London, Zoology, 9 (35), $179-180$. https://doi.org/10.1111/j.1096-3642.1867.tb00281.x

Lubbock, J. (1868) On Pauropus, a new type of centipede. Transactions of the Linnean Society of London, 26 (1), 181-190, pl. 10. https://doi.org/10.1111/j.1096-3642.1968.tb00504.x

Martínez-Muñoz, C.A. (2019) Proposal of Myriatrix, a virtual research environment for the International Society for Myriapodology. International Society for Myriapodology Newsletter, 4, 25-26. [https://www.myriapodology.org/newsletter/newsletter/CIMnewsletter2019.pdf]

Qian, C.-Y., Dong, Y., Bernard, E.C. \& Sun, H.-Y. (2015) Records of Pauropoda (Pauropodidae, Brachypauropodidae, Eurypauropodidae, Sphaeropauropodidae) from China, with a key to the species and descriptions of three new species of Decapauropus. Zootaxa, 4006 (3), 521-539. https://doi.org/10.11646/zootaxa.4006.3.6

Raphael, S. (1970) The publication dates of the Transactions of the Linnean Society of London, Series I, 1791-1875. Biological Journal of the Linnean Society, 2 (1), 61-76. https://doi.org/10.1111/j.1095-8312.1970.tb01688.x

Scheller, U. (2008) A reclassification of the Pauropoda (Myriapoda). International Journal of Myriapodology, 1 (1), 1-38. https://doi.org/10.1163/187525408X316730

Scheller, U. (2011) Pauropoda. In: Minelli, A. (Ed.), Treatise on Zoology-Anatomy, Taxonomy, Biology. The Myriapoda. Vol. 1. Brill, Leiden, pp. 467-508. https://doi.org/10.1163/9789004188266_022

The Fellegship of the Rings (2020 onwards) Myriatrix. Available from: http://myriatrix.myspecies.info (accessed 25 March 2021)

Yin, Z.-W., Li, L.-Z. \& Zhao, M.-J. (2010) Contributions to the knowledge of the myrmecophilous pselaphines (Coleoptera, Staphylinidae, Pselaphinae) from China. III. Two new genera and two new species of the subtribe Batrisina (Staphylinidae, Pselaphinae, Batrisitae) from a colony of Lasius niger (Hymenoptera, Formicidae, Formicinae) in East China. Sociobiology, 55 (1), Part B, 241-253. [https://www.researchgate.net/publication/291460213] 